\title{
Low-temperature homoepitaxial growth on Sil111) through a Pb monolayer
}

\section{Citation}

Evans, P. G., O. D. Dubon, J. F. Chervinsky, F. Spaepen, and J. A. Golovchenko. 1998. LowTemperature Homoepitaxial Growth on Si(111) through a Pb Monolayer. Applied Physics Letters 73, no. 21: 3120. doi:10.1063/1.122692.

\section{Published Version}

doi:10.1063/1.122692

\section{Permanent link}

http://nrs.harvard.edu/urn-3:HUL.InstRepos:29405826

\section{Terms of Use}

This article was downloaded from Harvard University's DASH repository, and is made available under the terms and conditions applicable to Other Posted Material, as set forth at http:// nrs.harvard.edu/urn-3:HUL.InstRepos:dash.current.terms-of-use\#LAA

\section{Share Your Story}

The Harvard community has made this article openly available.

Please share how this access benefits you. Submit a story.

Accessibility 


\title{
Low-temperature homoepitaxial growth on $\mathrm{Si}(111)$ through a $\mathrm{Pb}$ monolayer
}

\author{
P. G. Evans, O. D. Dubon, J. F. Chervinsky, F. Spaepen, ${ }^{\text {a) }}$ and J. A. Golovchenko \\ Division of Engineering and Applied Sciences, Harvard University, Cambridge, Massachusetts 02138
}

(Received 29 July 1998; accepted for publication 25 September 1998)

\begin{abstract}
A monolayer of $\mathrm{Pb}$ mediates high-quality homoepitaxial growth on $\mathrm{Si}$ (111) surfaces at temperatures where growth with other overlayer elements or on bare surfaces leads to amorphous or highly defective crystalline films. Nearly defect-free epitaxy proceeds for film thicknesses up to $1000 \AA$ with no sign that this is an upper limit. The minimum temperature for high-quality epitaxy depends on the substrate miscut. For a $0.2^{\circ}$ miscut, the minimum temperature is $340^{\circ} \mathrm{C}$. Films grown on

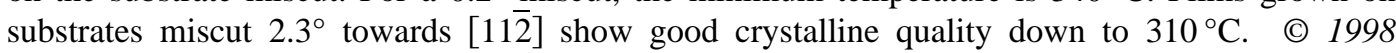
American Institute of Physics. [S0003-6951(98)01747-1]
\end{abstract}

Since the discovery that thin metal overlayers on Si surfaces can change the growth mode of deposited semiconductor films ${ }^{1}$ much work has been devoted to describing and exploiting the processes by which growth occurs. ${ }^{2,3}$ Characteristic features of the growth of semiconductor films through metal layers include the promotion of epitaxial growth at low temperatures and the segregation of the overlayer impurity to the surface of the growing film. Elements from groups III and $\mathrm{V},{ }^{4}$ as well as $\mathrm{Au}^{5,6}$ and $\mathrm{Sn},{ }^{7}$ have been shown to promote $\mathrm{Si}$ (111) homoepitaxy at temperatures lower than those necessary on bare surfaces. Reducing the growth temperature mitigates the effects of dopant diffusion, reaction and evaporation of surface metallizations, and thermal stress. With the exception of $\mathrm{Au}$, overlayer elements have been used to produce only limited film thicknesses, between 10 and $200 \AA$. All of the previously studied elements except $\mathrm{Sn}$ are electrically active impurities in $\mathrm{Si}$ and $\mathrm{Ge}$, further limiting their practical use. The promising results using Sn have not been followed up with a study of thicker films and were achieved only when the Sn overlayers were deposited or annealed with the substrate at $500{ }^{\circ} \mathrm{C}$.

In this letter we report homoepitaxial growth on $\mathrm{Si} \mathrm{(111)}$ at temperatures of $340^{\circ} \mathrm{C}$ on low-miscut substrates and $310^{\circ} \mathrm{C}$ on vicinal substrates using a $1 \mathrm{ML}(1 \mathrm{ML}=7.83$ $\times 10^{14}$ atoms $/ \mathrm{cm}^{2}$ ) $\mathrm{Pb}$ overlayer. We have grown films up to $1000 \AA$ A thick with no sign of decreasing quality with increasing thickness. As with other overlayer elements, the $\mathrm{Pb}$ layer segregates from the growing crystal to stay at the surface. The $310^{\circ} \mathrm{C}$ growth temperature represents an improvement of $150{ }^{\circ} \mathrm{C}$ in the temperature at which thick, high-quality homoepitaxial $\mathrm{Si}$ (111) films may be grown using Au overlayers and an improvement of approximately $350^{\circ} \mathrm{C}$ compared to growth on bare surfaces. ${ }^{8}$ Without $\mathrm{Pb}$, epitaxial growth at these temperatures breaks down within a few nanometers of the substrate-film interface, resulting in an amorphous film.

Previous studies of the behavior of $\mathrm{Pb}$ on $\mathrm{Si}$ (111) surfaces have shown that $\mathrm{Pb}$ allows near-surface $\mathrm{Si}$ atoms to move at low temperatures. For example, with $1 \mathrm{ML} \mathrm{Pb}$ the $7 \times 7$ reconstruction of the clean surface is changed to an incommensurate arrangement after annealing to temperatures

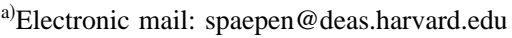

below $300{ }^{\circ} \mathrm{C} .{ }^{9}$ The change in reconstruction indicates that the $\mathrm{Pb}$ enables the removal of the stacking fault present in half of the $7 \times 7$ unit cell. In addition, atomic scale $\mathrm{Pb}$ diffusion on the $\mathrm{Si}$ (111) $7 \times 7$ surface has been observed at temperatures as low as $25^{\circ} \mathrm{C} .{ }^{10}$ As in the case of Sn, there are no known electronic deep levels associated with $\mathrm{Pb}$ impurities in $\mathrm{Si}^{11}{ }^{11}$ Recent work using $\mathrm{Pb}$ layers to promote the growth of $\mathrm{Si}^{12}$ and $\mathrm{Ge}^{13}$ films has been limited to films a few atomic layers thick, deposited at or near room temperature.

The 500- $\mu \mathrm{m}$-thick Si (111) wafers used in this study were cleaved into $1 \mathrm{~cm} \times 2 \mathrm{~cm}$ samples, chemically oxidized by the Shiraki process, ${ }^{14}$ and loaded into an ultrahigh vacuum growth chamber with a base pressure of $1 \times 10^{-10}$ Torr. To investigate the effect of miscut on growth quality, we used two types of wafers, one miscut $0.2 \pm 0.1^{\circ}(0.1-0.4$ $\Omega \mathrm{cm}, \mathrm{P}$ doped) and the other miscut $2.3 \pm 0.1^{\circ}$ towards [11 $\left.\overline{2}\right]$ $(>1000 \Omega \mathrm{cm}, \mathrm{P}$ doped). Using direct current resistive heating, each sample was degassed at $500^{\circ} \mathrm{C}$ for one hour, heated to $850^{\circ} \mathrm{C}$ to remove the oxide, cooled at a maximum rate of $1{ }^{\circ} \mathrm{C} / \mathrm{s}$ to $500{ }^{\circ} \mathrm{C}$ and then slowly cooled to the growth temperature. Because the thermal time constants of the sample holder system were long, we left each sample at the growth temperature for up to $24 \mathrm{~h}$ prior to $\mathrm{Pb}$ and $\mathrm{Si}$ depositions to achieve steady-state heat flow conditions. Sample temperatures were measured with an optical pyrometer, calibrated to the resistance of a sample that displayed intrinsic variation of the carrier concentration with temperature above $150{ }^{\circ} \mathrm{C}$. The resistance of the intrinsic sample was a sensitive function of temperature in the range of interest. All temperatures are accurate to within $\pm 10^{\circ} \mathrm{C}$.

Depositions of $\mathrm{Pb}$ and $\mathrm{Si}$ were done using an effusion cell and an electron beam heated rod, respectively. Lead coverages were determined in situ to within 5\% using Rutherford backscattering spectrometry (RBS). The Si deposition rates were $0.12 \pm 0.02 \AA / \mathrm{s}$ at a system pressure of approximately $2 \times 10^{-9}$ Torr. The evaporation sources were masked to produce partially overlapping regions in which $\mathrm{Pb}$ and $\mathrm{Si}$ were deposited, allowing simultaneous growth of films with and without $1 \mathrm{ML} \mathrm{Pb}$. Imperfections in the masking process yielded a low $\mathrm{Pb}$ flux, below $1 \%$ of that in the direct $\mathrm{Pb}$ beam, to the area where nominally only $\mathrm{Si}$ was to be deposited. At all growth temperatures studied, $295-340^{\circ} \mathrm{C}$, with 1 ML $\mathrm{Pb}$ coverage the sample displayed a $1 \times 1$ low energy 


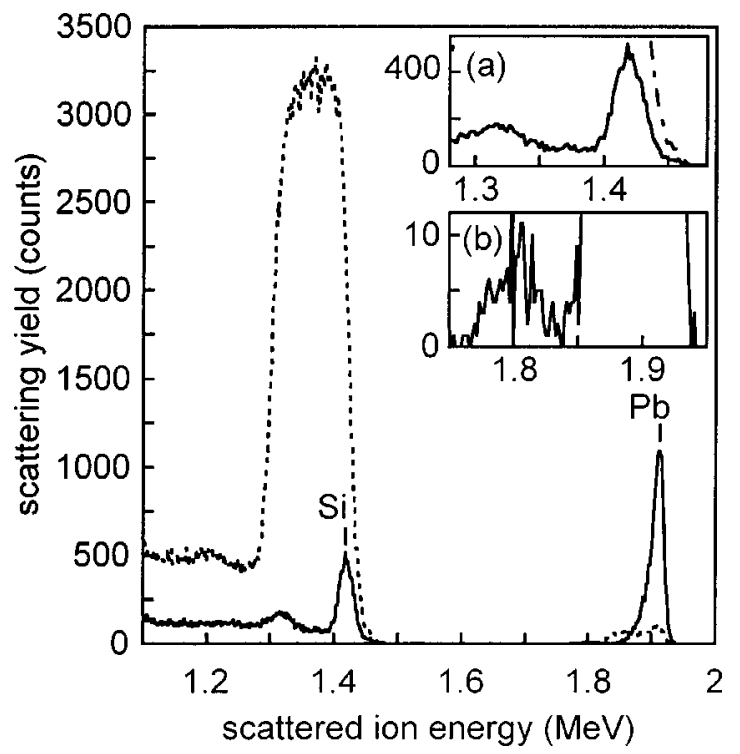

FIG. 1. Ion channeling spectra for $1000 \AA \mathrm{Si}$ films grown on $\mathrm{Si}$ (111) at $340{ }^{\circ} \mathrm{C}$ with (solid line) and without (dashed line) codeposition to achieve 1 ML steady-state $\mathrm{Pb}$ coverage. The improvement in crystal quality with 1 $\mathrm{ML} \mathrm{Pb}$ present during growth dramatically reduces the scattering yield from the film. Inset are enlargements of the vicinities of (a) the Si surface peak, and (b) the $\mathrm{Pb}$ peak at $1.8 \mathrm{MeV}$ due to $0.01 \mathrm{ML} \mathrm{Pb}$ at the substrate-film interface.

electron diffraction (LEED) pattern, which is consistent with previous observations. ${ }^{15}$ Upon cooling the samples to room temperature after growth, we observed the high-coverage rotated incommensurate (IC) LEED pattern in the areas of the sample where $1 \mathrm{ML} \mathrm{Pb}$ was present. ${ }^{9}$ Regions on which neither $\mathrm{Si}$ nor $\mathrm{Pb}$ was deposited displayed bright, sharp $7 \times 7$ LEED patterns.

We have found that significant desorption of $\mathrm{Pb}$ occurs at temperatures above $280^{\circ} \mathrm{C}$. In order to keep the $\mathrm{Pb}$ coverage constant during growth of the $\mathrm{Si}$ film, $\mathrm{Si}$ and $\mathrm{Pb}$ were codeposited. Achieving a steady-state $1 \mathrm{ML}$ coverage of $\mathrm{Pb}$ required a $\mathrm{Pb}$ flux that ranged from $0.12 \mathrm{ML} / \mathrm{min}$ at $295^{\circ} \mathrm{C}$ to $0.18 \mathrm{ML} / \mathrm{min}$ at $340^{\circ} \mathrm{C}$. These fluxes correspond to desorption rates that are several times higher than one would expect due to evaporation from bulk $\mathrm{Pb}$, according to vapor pressure measurements. ${ }^{16}$ Similarly enhanced desorption rates have been observed at higher temperatures. ${ }^{9}$ The rapid increase in desorption rate at coverages just higher than 1 ML, as observed in that study, simplifies the task of achieving $1 \mathrm{ML} \mathrm{Pb}$ through codeposition.

The samples were characterized after growth by ex situ 2 $\mathrm{MeV}{ }^{4} \mathrm{He}^{+}$ion channeling measurements with the incident beam along [111] and the detector aligned in a glancing exit geometry. Figure 1 shows two spectra from a film deposited at $340{ }^{\circ} \mathrm{C}$ on a low-miscut sample. The film grown on a region of the sample with only incidental $\mathrm{Pb}$ coverage (approximately $0.2 \mathrm{ML} \mathrm{Pb}$ distributed throughout the film) shows scattering consistent with growth of a $1000 \AA$ amorphous layer. We observe no change in the growth of the amorphous film due to the small amount of $\mathrm{Pb}$ present; films with no $\mathrm{Pb}$ contamination are identical. In comparison, the film grown with codeposition to maintain $1 \mathrm{ML} \mathrm{Pb}$ during growth shows a dramatic reduction in scattering yield. The minimum yield, $\chi_{\min }$, which is the ratio of the ion-scattering yield behind the Si surface peak for the incident beam in a Downloaded 14 Dec 2005 to 128.103.60.225. Redistribution subje
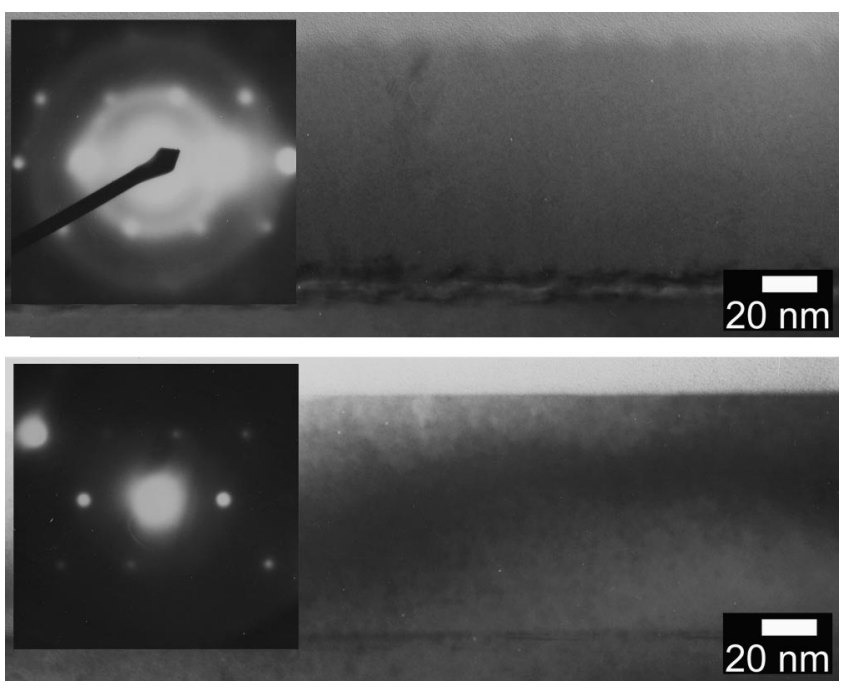

FIG. 2. Transmission electron micrographs with the incident beam along a $\langle 110\rangle$ direction from $\mathrm{Si}$ films grown at $340^{\circ} \mathrm{C}$ on $\mathrm{Si}$ (111) without $\mathrm{Pb}$ (top) and with codeposition to achieve a $1 \mathrm{ML} \mathrm{Pb}$ overlayer (bottom). Electron diffraction patterns (inset) reveal that the film grown without $\mathrm{Pb}$ is amorphous and that the film with $\mathrm{Pb}$ is an epitaxial extension of the crystal. The crystalline reflections in the top diffraction pattern are from the substrate.

channeled direction to the yield for random incidence, is 2.4 $\pm 0.3 \%$ for the grown sample, identical within measurement error to $\chi_{\min }$ measured for a clean $\mathrm{Si}$ (111) sample on which $1 \mathrm{ML} \mathrm{Pb}$ had been deposited, $2.2 \pm 0.3 \%$. The area under the peak at $1.9 \mathrm{MeV}$ due to scattering from $\mathrm{Pb}$ corresponds to a $\mathrm{Pb}$ coverage of $1.07 \pm 0.05 \mathrm{ML}$. Small islands of $\mathrm{Pb}$ on the surface are responsible for the slight elongation of the $\mathrm{Pb}$ peak towards low energy. A lesser peak at $1.8 \mathrm{MeV}$ corresponds to $0.01 \mathrm{ML} \mathrm{Pb}$ at the substrate-film interface. The silicon surface peak at $1.4 \mathrm{MeV}$ is indistinguishable from that of $\mathrm{Si}$ (111) with $1 \mathrm{ML} \mathrm{Pb}$ on which no homoepitaxial film has been grown, indicating no detectable increase in disorder at the surface. The subsurface scattering peak at 1.3 $\mathrm{MeV}$, a "close encounter" 17 between channeled ions and $\mathrm{Si}$ atoms at lattice sites, also appears in spectra taken on bare surfaces. That the surfaces remain highly ordered after growth is confirmed by the observation of the IC LEED pattern.

Images and diffraction patterns obtained by crosssectional transmission electron microscopy (TEM) with the incident beam along a $\langle 110\rangle$ direction are shown in Fig. 2 for the films for which ion channeling spectra appear in Fig. 1. The film grown without $\mathrm{Pb}$ codeposited exhibits a diffraction pattern consisting of rings superimposed on the sharp spots due to diffraction from the substrate. The ring spacing indicates that the film is amorphous $\mathrm{Si}^{18}$ The amorphous film has a rough interface with the substrate indicating initial polycrystalline growth. In comparison, the film grown with 1 $\mathrm{ML} \mathrm{Pb}$ shows high-quality epitaxy. We associate the line visible at the substrate-film interface with the $0.01 \mathrm{ML}$ of trapped $\mathrm{Pb}$. The film produces a sharp bright diffraction pattern identical to that of the substrate.

Films grown with codeposition rates giving $\mathrm{Pb}$ coverages less than $1 \mathrm{ML}$ are defective. Examination of these films by TEM shows the defects to be stacking faults that nucleate at the substrate-film interface. At $340{ }^{\circ} \mathrm{C}$, growth with $0.90 \pm 0.05 \mathrm{ML} \mathrm{Pb}$ consistently yields films with $\chi_{\min }$ to AIP license or copyright, see http://apl.aip.org/apl/copyright.jsp 


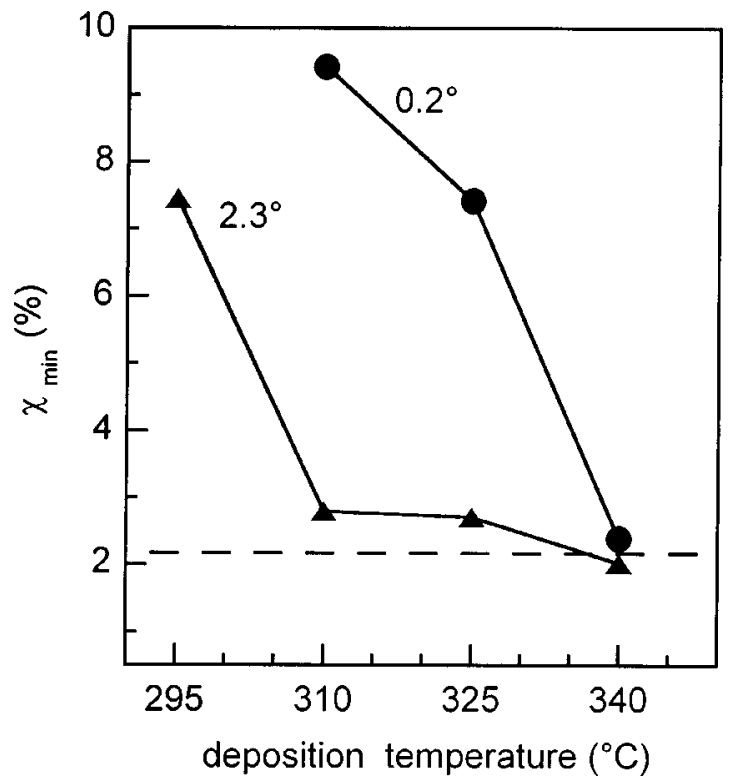

FIG. 3. The minimum yield $\chi_{\min }$ measured for 500-1200 ̊ films grown on $0.2^{\circ}$ (circles) and $2.3^{\circ}$ (triangles) miscut $\mathrm{Si}$ (111) substrates. Growth of high-quality films is possible at lower temperatures on the $2.3^{\circ}$ miscut substrates. The dashed line indicates $\chi_{\min }$ measured for a wafer on which $1 \mathrm{ML}$ $\mathrm{Pb}$ had been deposited.

$=5 \%$, due to grown-in defects. With more than $1 \mathrm{ML} \mathrm{Pb}$ present on the surface, the excess $\mathrm{Pb}$ forms threedimensional islands which can extend up to $1 \mu \mathrm{m}$ in height, as measured by scanning electron microscopy. When the total $\mathrm{Pb}$ coverage is only slightly greater than the equivalent of $1 \mathrm{ML}$, ion channeling measurements indicate that the islands are surrounded by $1 \mathrm{ML} \mathrm{Pb}$. Under these conditions, high quality epitaxial growth can still proceed. The formation of $\mathrm{Pb}$ islands at the lowest growth temperatures studied is consistent with the high mobility of $\mathrm{Pb}$ on the $\mathrm{Si}$ (111) surface.

For the samples produced from the low-miscut substrate, the quality of the grown film deteriorates for growth temperatures below $340^{\circ} \mathrm{C}$. The minimum yield $\chi_{\min }$ increases rapidly with decreasing growth temperature, indicating a sharp decrease in the crystalline quality of the film. Films grown at $310^{\circ} \mathrm{C}$ have $\chi_{\min }=9 \%$. As is the case at higher temperatures with homoepitaxy on bare $\mathrm{Si}$ (111), stacking faults nucleating at or near the substrate-film interface and propagating through the film are the dominant extended defect. We find, however, that the minimum temperature at which a high-quality film can be grown is a function of the miscut orientation of the substrate. Figure 3 compares the measured $\chi_{\min }$ of $500-1200 \AA$ films grown on $0.2^{\circ}$ and $2.3^{\circ}$ miscut substrates. Films of excellent crystalline quality can be grown on the $2.3^{\circ}$ miscut samples for substrate temperatures as low as $310^{\circ} \mathrm{C}$. The lowering of the minimum temperature at which high-quality growth is observed from $340^{\circ} \mathrm{C}$ for low-miscut substrates to $310^{\circ} \mathrm{C}$ for stepped substrates is a clear indication that the step edges have a kinetic role in the film growth. Reflection electron microscopy experiments on Sn-mediated Si (111) homoepitaxy ${ }^{7}$ and ion channeling experiments with Au overlayers ${ }^{6}$ reached similar conclusions. We continue to investigate the mechanism responsible for the high-quality growth in the $\mathrm{Pb}$-mediated case.

The authors acknowledge D. Loretto, A. J. Garrat-Reed, and $\mathrm{Y}$. Lu for assistance with electron microscopy and for helpful discussions. We also acknowledge preliminary work on the role of $\mathrm{Pb}$ in Si homoepitaxy by Li-Chung Wei and G. D. Wilk. This work was supported by the Harvard University Materials Research Science and Engineering Center (NSF DMR 9400396). Electron microscopy was performed in the Shared Experimental Facility of the Center for Materials Science and Engineering at M.I.T. (NSF DMR 9400334).

${ }^{1}$ M. Copel, M. C. Reuter, E. Kaxiras, and R. M. Tromp, Phys. Rev. Lett. 63, 632 (1989).

${ }^{2}$ D. Kandel and E. Kaxiras, Phys. Rev. Lett. 75, 2742 (1995).

${ }^{3}$ B. R. A. Neves, M. S. Andrade, W. N. Rodrigues, G. A. M. Safar, M. V. B. Moreira, and A. G. de Olivera, Appl. Phys. Lett. 72, 1712 (1998).

${ }^{4}$ M. Horn-von Hoegen, J. Falta, M. Copel, and R. M. Tromp, Appl. Phys. Lett. 66, 487 (1995); B. Voigtlander, A. Zinner, T. Weber, and H. P. Bonzel, Phys. Rev. B 51, 7583 (1995).

${ }^{5}$ G. D. Wilk, R. E. Martinez, J. F. Chervinsky, F. Spaepen, and J. A. Golovchenko, Appl. Phys. Lett. 65, 866 (1994).

${ }^{6}$ G. D. Wilk, J. F. Chervinsky, F. Spaepen, and J. A. Golovchenko, Appl. Phys. Lett. 70, 2553 (1997).

${ }^{7}$ S. Iwanari and K. Takayanagi, Jpn. J. Appl. Phys., Part 2 30, L1978 (1991).

${ }^{8}$ H. P. Zeindl, V. Fuenzalida, J. Messarosch, I. Eisele, H. Oppolzer, and V. Huber, J. Cryst. Growth 81, 231 (1987).

${ }^{9}$ E. Ganz, I.-S. Hwang, F. Xiong, S. K. Theiss, and J. Golovchenko, Surf. Sci. 257, 259 (1991).

${ }^{10}$ J. M. Gómez-Rodríguez, J. J. Sáenz, A. M. Baró, J.-Y. Veuillen, and R. C. Cinti, Phys. Rev. Lett. 76, 799 (1996).

${ }^{11}$ A. Rohatgi, J. R. Davis, R. H. Hopkins, and P. G. McMullin, Solid-State Electron. 26, 1039 (1983).

${ }^{12}$ H. Zhao, S. P. Tear, and A. H. Jones, Surf. Sci. 307-309, 645 (1994).

${ }^{13}$ I.-S. Hwang, T.-C. Chang, and T. T. Tsong, Phys. Rev. Lett. 80, 4229 (1998).

${ }^{14}$ A. Ishizaka and Y. Shiraki, J. Electrochem. Soc. 133, 666 (1986).

${ }^{15}$ I.-S. Hwang, R. E. Martinez, C. Liu, and J. A. Golovchenko, Surf. Sci. 323, 241 (1995).

${ }^{16} \mathrm{~F}$. Rosebury, Handbook of Electron Tube and Vacuum Techniques (Addison-Wesley, Reading, 1965).

${ }^{17}$ L. C. Feldman, J. W. Mayer, and S. T. Picraux, Materials Analysis by Ion Channeling: Submicron Crystallography (Academic, New York, 1982).

${ }^{18} \mathrm{R}$. Zallen, The Physics of Amorphous Solids (Wiley Interscience, New York, 1983), pp. 76-81. 